\title{
Selective Blockade of Drug-induced Place Preference Conditioning by ACPC, a Functional NDMA-receptor Antagonist
}

\author{
Marius Papp, Piotr Gruca, and Paul Willner
}

ACPC (1-aminocyclopropanecarboxylic acid) is a partial agonist at the strychnine-insensitive glycine receptor site on the NMDA receptor complex, and a functional NMDA antagonist. A series of experiments was conducted to assess the effects of ACPC in a biased place conditioning paradigm. As previously reported, ACPC itself did not support either appetitive or aversive place conditioning. However, co-administration of ACPC $(200 \mathrm{mg} / \mathrm{kg})$ blocked the acquisition of place preferences conditioned using $a$ variety of psychoactive drugs (amphetamine, cocaine, nomifensine, diazepam, morphine, nicotine). No tolerance was seen to this effect following two weeks of chronic ACPC administration. Overall, ACPC did not affect the expression of place conditioning when administered immediately before the post-conditioning test. However, these effects appeared somewhat variable between drugs, and further analysis showed that ACPC did block the expression of preferences conditioned with some drugs (diazepam, morphine, nicotine), but not others (amphetamine, cocaine, nomifensine). The effects of ACPC could not be accounted for by state dependence, as ACPC blocked morphine and cocaine place preferences when administered during both the acquisition and the expression phase of conditioning. In contrast to the blockade by ACPC of drug-induced place preferences, $A C P C$ had no effect on the acquisition of place preferences conditioned using a variety of natural non-drug reinforcers (food, sucrose, social interaction, novelty).

$A C P C$ also had no effect on the acquisition of drug-induced place aversions (naloxone, picrotoxin). Thus, ACPC selectively blocked appetitive conditioning by drug reinforcers, without affecting either appetitive conditioning by natural reinforcers or drug-induced aversions. As place preference conditioning has been demonstrated to have high predictive validity for detecting compounds with an abuse potential in humans, this selective action suggests that ACPC might have some clinical utility in the treatment of addiction, without affecting responses to natural rewards. [Neuropsychopharmacology 27:727-743, 2002] (C) 2002 American College of Neuropsychopharmacology. Published by Elsevier Science Inc.
From the Institute of Pharmacology, Polish Academy of Sciences, Krakow, Poland (MP, PG), and Centre for Substance Abuse Research, University of Wales, Swansea, UK (PW).

Address correspondence to: P. Willner, University of Wales Swansea, Swansea SA2 8PP, UK. Tel.: +44-1792-295844; Fax: +441792-295679; E-mail: p.willner@ swansea.ac.uk

Received May 9, 2001; revised March 22, 2002; accepted March 28, 2002.

Online publication: 4/18/02 at www.acnp.org/citations/Npp 041802284 .
KEY WORDS: ACPC; Addiction; Drug aversion; Drug reward; Natural reward; Place conditioning; State dependence; Rat

The treatment of drug addiction has two targets: cessation or reduction of use, and maintenance of those gains. During the maintenance phase, a number of factors have been identified that predispose to relapse. These include stimuli associated with drug taking (O'Brien et al. 1998). The place preference conditioning procedure has been used extensively as an animal model for investigating the rewarding properties of drug-conditioned stimuli. In this procedure, 
the animal experiences the effects of a drug while confined in a distinctive environment; subsequently the animal is offered a choice between the drug-paired environment and an environment that has been experienced in the drug-free state. Subject to certain methodological considerations, a preference for the drug-paired environment is interpreted to mean that the environment has acquired secondary reinforcing properties as a consequence of its pairing with a primary reinforcer. Drugs that support the development of a conditioned place preference (CPP) are generally those that are abused by people (e.g. psychostimulants, opioids, benzodiazepines, alcohol, nicotine), while drugs that do not support CPP are typically not abused (e.g. neuroleptics, antidepressants, antihistamines) (Carr et al. 1989; Schechter and Calcagnetti 1993; Calcagnetti and Schechter 1998; Tzschentke 1998). In addition to drug rewards, CPP can also be used to study the reinforcing properties of natural rewards, and a diverse range of rewards has been investigated, which, in addition to reinforcers that are consumed such as food or sucrose solutions, also include less obvious reinforcers such as social interaction (Calcagnetti and Schechter 1992) and novelty (Parker 1992). This versatile procedure can also be used to investigate drug-induced conditioned place aversions, which are inferred from a decrease in the preference displayed for a drug-paired environment (Carr et al. 1989; Schechter and Calcagnetti 1992; Calagnetti and Schechter 1998).

The excitatory neurotransmitter glutamate has been implicated in a variety of central nervous system disorders, and antagonists of the N-methyl-D-aspartate (NMDA) subtype of glutamate receptor have been shown in animal models to have neuroprotective, anticonvulsant, anxiolytic and antidepressant properties (Meldrum 1985; Olney 1989; Paul et al. 1994; Papp and Moryl 1994a; Witkin 1995). In addition to these indications, both competitive and uncompetitive NMDA receptor antagonists have also been found to block the acquisition of place preferences conditioned with cocaine (Cervo and Samanin 1995; Kotlinska and Biala 2000), amphetamine (Tzschentke and Schmidt 1997) and morphine (Tzschentke and Schmidt 1995; Kim et al. 1996; Popik et al. 1998), suggesting a possible role in the treatment of drug addiction.

However, both competitive and uncompetitive NMDA receptor antagonists have been reported to produce severe psychostimulant and psychotomimetic-like effects in animal models (Balster 1987; Koek et al. 1988; Willetts et al. 1990; Carter 1995), and severe adverse side effects were seen in clinical trials of the competitive NMDA receptor antagonists D-CPP-ene and CGS 19755 (Grotta et al. 1995; Sveinbjornsdottir et al. 1993). Furthermore, CPP experiments have established that both classes of NMDA antagonist have rewarding properties (Tzschentke and Schmidt 1995; Papp et al. 1996; Tzschentke 1998), which implies that they would prob- ably also have abuse potential. For all of these reasons, directly-acting NMDA antagonists are unlikely to be developed for clinical use.

The NMDA receptor complex has multiple regulatory sites, including a strychnine-insensitive glycinebinding site, where the amino acid glycine functions as an obligatory co-agonist (Kleckner and Dingledine 1988; Scatton 1993). Because synaptic concentrations of glycine are at or near saturation, functional antagonism of the glycine receptor, and therefore, functional NMDA antagonism, can be achieved either by compounds that act as glycine site antagonists, or by compounds that act as agonists but have low intrinsic activity (Carter 1992; Fossom et al. 1995). Numerous studies have demonstrated that glycine site antagonists and partial agonists share many of the pharmacological actions of directlyacting NMDA antagonists, but without their psychotomimetic effects (Anthony and Nevins 1993; Dunn et al. 1992; Faiman et al. 1994; Rundfeldt et al. 1994; Trullas et al. 1991; Cherkovsky 1995; Fossom et al. 1995; KarczKubicha et al. 1999). Also in contrast to directly acting NMDA antagonists, glycine site antagonists and partial agonists fail to display rewarding properties in CPP experiments (Bespalov et al. 1994; Papp et al. 1996; Kotlinska and Biala 1999).

ACPC (1-aminocyclopropanecarboxylic acid) is a high affinity partial agonist at strychnine-insensitive glycine receptors (Marvizon et al. 1989). There is also evidence that ACPC might act directly as a low-affinity antagonist at the NMDA receptor (Nahum-Levy et al. 1999). ACPC has been found to produce anticonvulsant, neuroprotective, anxiolytic and antidepressantlike effects in rats and mice (Anthony and Nevins 1993; von Lubitz et al. 1992; Faiman et al. 1994; Trullas et al. 1991; Papp and Moryl 1996), and was recently reported to block the acquisition of morphine CPP (Kotlinska and Biala 2000). In this study we report on the effects of $\mathrm{ACPC}$ on the acquisition and expression of place preferences conditioned to a wide variety of drug and natural reinforcers, and on drug-induced conditioned place aversions.

\section{METHODS}

\section{Subjects}

Male Wistar rats weighing about $300 \mathrm{~g}$ (Gorzkowska, Warsaw) were housed in groups of five in plastic cages $(40 \times 25 \times 15 \mathrm{~cm})$, with food and water freely available, except as described below. The rats were maintained on a 12-h light/dark cycle (lights on at 8 A.M.), at a temperature of $22 \pm 2^{\circ} \mathrm{C}$. The study was conducted in compliance with the Animal Protection Bill of August 21 1997, and was approved by the Bioethical Committee at the Institute of Pharmacology, Polish Academy of Sciences, Krakow, Poland. 


\section{Apparatus}

The animals were trained and tested in ten identical wooden chambers, consisting of white and black compartments $(30 \times 20 \times 25 \mathrm{~cm})$ with different floor textures (plain wood or wire mesh respectively), and a gray central area $(12 \times 20 \times 25 \mathrm{~cm})$ with a plain wood floor. The black and white compartments were separated from the central gray compartment by guillotine doors. In this apparatus, animals given access to the whole apparatus typically spend more time in the black compartment than in the white compartment. Hence, the black compartment is said to be "preferred" and the white compartment "non-preferred".

\section{Place Conditioning Procedure}

Except for minor variations described below, essentially the same procedure was adopted for all experiments.

On the first three days of each experiment, the animals were placed individually in the central compartment; after $5 \mathrm{~s}$ the guillotine doors were gently raised by hand and removed, and the rat was allowed to explore the whole chamber for $10 \mathrm{~min}$ per day. On day 4 the procedure was repeated, and the time spent in each compartment (both front feet in the compartment) was recorded manually, by an observer viewing the apparatus through a mirror located $1.5 \mathrm{~m}$ above each chamber.

Animals then underwent a series of three or four (see below) pairs of conditioning trials, presented at a rate of one trial per day, during which they were confined in either the white or the black compartment, on alternate days. Biased procedures were used: in place preference experiments, the animals received either a drug or a natural reward (see below) before confinement in the white (non-preferred) compartment, and a vehicle injection or no treatment, as appropriate, before confinement in the black (preferred) compartment. In place aversion experiments, the animals received a drug injection before confinement in the black (preferred) compartment and a vehicle injection before confinement in the white (non-preferred) compartment. Treatments and chambers alternated, beginning with a vehicle trial.

In the final session, which was conducted in the absence of conditioning drugs and rewards, the animals were placed in the central compartment, and after $5 \mathrm{~s}$ the guillotine doors were raised and the time spent in each compartment was measured manually, by a blinded observer, in a 10-min post-conditioning test.

\section{Experiment 1: Effects of ACPC Alone}

In two subexperiments, ACPC was used as the conditioning drug, administered either on the white or the black side of the apparatus (place preference and place aversion conditioning, respectively). On one of each of three pairs of 60 -min trials, groups of animals $(n=10)$ received vehicle or ACPC $(200 \mathrm{mg} / \mathrm{kg}) 30 \mathrm{~min}$ prior to confinement in either the white or the black compartment. In the alternate trials, all animals received vehicle injections prior to confinement on the opposite side. In a third subexperiment, groups of animals $(n=8)$ received vehicle or ACPC $(200 \mathrm{mg} / \mathrm{kg})$ prior to confinement in both the white and the black compartments. In a fourth subexperiment no drug was administered during conditioning, but groups of animals $(n=10)$ received vehicle or ACPC $(200 \mathrm{mg} / \mathrm{kg}) 30 \mathrm{~min}$ before the post-conditioning test.

\section{Experiment 2: Effects of ACPC on Drug-induced Conditioned Place Preference}

In six separate subexperiments, place preferences were established, as described above, using amphetamine, cocaine, diazepam, morphine, nicotine, and nomifensine. (See Drugs for details of doses and drug administration procedures.) In each experiment, one subgroup received vehicle injections before both conditioning trials, and three subgroups received vehicle before confinement in the black compartment and the conditioning drug before confinement in the white compartment. One of these subgroups received only the conditioning drug; a second subgroup (ACPC in acquisition) was administered ACPC $(200 \mathrm{mg} / \mathrm{kg}) 30 \mathrm{~min}$ before vehicle and drug injections on conditioning trials; the third subgroup (ACPC in expression) was administered ACPC $(200 \mathrm{mg} / \mathrm{kg}) 30 \mathrm{~min}$ before the post-test.

The number and duration of conditioning sessions were: amphetamine: four pairs of 60 -min sessions; cocaine: four pairs of 45-min sessions; diazepam: three pairs of 60-min sessions; morphine: three pairs of $45-$ min sessions; nicotine: three pairs of 50-min sessions; nomifensine: four pairs of 60 -min sessions. All group sizes were $n=10$, except for the nomifensine experiment, where $n=8$ for controls and $n=9$ for each of the three nomifensine groups.

\section{Experiment 3: Effects of ACPC on Reward-induced Conditioned Place Preference.}

In five separate subexperiments, non-drug natural rewards (details below) were used to induce place preference conditioning. In each experiment, one subgroup was never rewarded, while three subgroups were administered rewards while confined in the white compartment, but not the black compartment. One of these subgroups received only the conditioning stimulus; a second subgroup (ACPC in acquisition) was administered ACPC $(200 \mathrm{mg} / \mathrm{kg}) 30 \mathrm{~min}$ before conditioning trials, in either compartment; the third (ACPC in expression) was administered ACPC $(200 \mathrm{mg} / \mathrm{kg}) 30 \mathrm{~min}$ before the post-test. 
Experiments $3 a$ and 3b: Food Reward. For eight days prior to conditioning, animals were adapted to either $2 \mathrm{~h}$ (experiment $3 \mathrm{a}$ ) or $22 \mathrm{~h}$ (experiment $3 \mathrm{~b}$ ) daily food deprivation. Conditioning consisted of four pairs of 120min sessions. On rewarded trials, food (pre-weighed standard laboratory food pellets) was provided in a glass dish on the floor of the white compartment; food intake during the conditioning trial was measured by weighing the pellets remaining at the end of the trial. On non-rewarded days, animals were placed in the black compartment without food; they were fed for $2 \mathrm{~h}$ at random times after being returned to their home cages. All group sizes were $\mathrm{n}=10$.

Experiment 3c: Sucrose. For eight days prior to conditioning, animals were adapted to $2 \mathrm{~h}$ daily water deprivation, followed by $2 \mathrm{~h}$ access, in the home cage, to a bottle containing a $10 \%$ sucrose solution. Conditioning consisted of four pairs of 120 -min sessions. On rewarded trials, $10 \%$ sucrose was provided in a drinking bottle inserted through a hole in one wall, in the white compartment; sucrose intake was measured by weighing the bottle before and after the trial. Group sizes were: control, $\mathrm{n}=8$; sucrose alone, $\mathrm{n}=9$; sucrose + ACPC in acquisition or expression, $\mathrm{n}=9$.

Experiment 3d: Social Interaction. Conditioning consisted of four pairs of 70-min sessions. On rewarded trials, a male rat was introduced into the white compartment $10 \mathrm{~min}$ after the start of the session; a different intruder was used on each conditioning trial. Group sizes were $n=15$, except for the control group, for which $\mathrm{n}=10$.

Experiment 3e: Novelty. Animals first received two adaptation trials to the apparatus, followed by a pre-test, in which both compartments were available. On days 5, 7, and 9, 'conditioning' trials were conducted in which the animals were confined in the black compartment for 40 min; on days 4, 6 and 8, the animals remained in their home cages (except that subgroup 2 recevied ACPC injections). In the post-test, on day 10 , both compartments were available. All group sizes were $\mathrm{n}=10$.

\section{Experiment 4: Effect of Chronic ACPC on Drug-induced Conditioned Place Preference}

As any clinical use of ACPC would involve chronic treatment, we wished to establish whether tolerance occurred to the effects described in experiment 1 .

In three separate subexperiments, place preferences were established, as described above, using three drugs with different mechanisms of action, morphine, cocaine, and diazepam. (See Drugs for details of doses and drug administration.) In each experiment, one subgroup received daily vehicle injections beginning 14 days before conditioning and continuing through adap- tation and before both conditioning trials. Injections were $4 \mathrm{~h}$ before adaptation trials 1 and 3 , and $2 \mathrm{~h}$ after adaptation trial 2 (to avoid any associations between injections and the conditioning apparatus), and $30 \mathrm{~min}$ before conditioning trials. Two other subgroups received vehicle before confinement in the black compartment and the conditioning drug before confinement in the white compartment. One of these subgroups received only the conditioning drug, plus daily vehicle injections beginning 14 days before conditioning; the second subgroup (ACPC in acquisition) was administered ACPC $(200 \mathrm{mg} / \mathrm{kg})$ for 14 days prior to the start of the conditioning and $30 \mathrm{~min}$ before vehicle and drug injections on conditioning trials.

The number and duration of conditioning trials was as described above (experiment 2). Group sizes were $n=12$, except for the vehicle control groups, for which $\mathrm{n}=9$.

\section{Experiment 5: Control for State Dependence}

In this experiment, place preferences were established, as described above, using morphine and cocaine. Group 1 received vehicle injections before all conditioning trials and before the post-test. Groups 2 and 4 received vehicle before confinement in the black compartment and morphine or cocaine, respectively, before confinement in the white compartment; and vehicle before the post-test. Groups 3 and 5 were treated identically to groups 2 and 4, respectively, but also received ACPC before both vehicle and drug injections on conditioning trials, and before the post-test.

There were four pairs of 45-min conditioning sessions; group sizes were $\mathrm{n}=9($ groups $2,3,5)$ or $\mathrm{n}=10$ (groups 1, 4).

\section{Experiment 6: Effects of ACPC on Drug-induced Conditioned Place Aversion}

In two separate subexperiments, place aversions were established, as described above, using naloxone and picrotoxin as the conditioning drugs. (See Drugs for details of doses and drug administration.) In each experiment, one subgroup received vehicle injections before both conditioning trials, and three subgroups received vehicle before confinement in the white compartment and the conditioning drug before confinement in the black compartment. One of these subgroups received only the conditioning drug; a second subgroup (ACPC in acquisition) was administered ACPC (200 mg/kg) 30 min before vehicle and drug injections on conditioning trials; the third (ACPC in expression) was administered ACPC $(200 \mathrm{mg} / \mathrm{kg}) 30 \mathrm{~min}$ before the post-test. These treatments were identical to those described above (experiment 2). 
In both subexperiments, three pairs of 45 -min sessions were used. All group sizes were $n=10$, except for the picrotoxin + ACPC (acquisition) group, for which $\mathrm{n}=9$.

\section{Drugs}

D-amphetamine sulfate (Sigma, St. Louis, MO, USA) was injected $15 \mathrm{~min}$ before conditioning sessions at a dose of $1 \mathrm{mg} / \mathrm{kg}$ s.c. Cocaine $\mathrm{HCl}$ (Merck, Darmstadt, Germany) was injected $5 \mathrm{~min}$ before conditioning sessions at a dose of $20 \mathrm{mg} / \mathrm{kg}$ i.p. Diazepam (Polfa, Warsaw, Poland) was injected $30 \mathrm{~min}$ before conditioning sessions at a dose of $2.5 \mathrm{mg} / \mathrm{kg}$ i.p. Morphine $\mathrm{HCl}$ (Polfa) was injected $15 \mathrm{~min}$ before conditioning sessions at a dose of $1 \mathrm{mg} / \mathrm{kg}$ i.p. Nicotine bitartrate (RBI, Natick, MA, USA) was injected 10 min before conditioning sessions at a dose of $0.8 \mathrm{mg} / \mathrm{kg}$ s.c. Nomifensine maleate (RBI) was injected $15 \mathrm{~min}$ before conditioning sessions at a dose of $5 \mathrm{mg} / \mathrm{kg}$ i.p. Naloxone $\mathrm{HCl}$ (RBI) was injected 10 min before conditioning sessions at a dose of $0.7 \mathrm{mg} / \mathrm{kg}$ s.c. Picrotoxin (Sigma) was injected $20 \mathrm{~min}$ before conditioning sessions at a dose of $2 \mathrm{mg} / \mathrm{kg}$ i.p. 1-aminocyclopropanecarboxylic acid (ACPC) was obtained from Annovis Inc. (Aston, PA), and injected $30 \mathrm{~min}$ before either conditioning trials or drug injections, as described above, at a dose of $200 \mathrm{mg} / \mathrm{kg}$ i.p.

Diazepam was dissolved in $0.5 \%$ methylcellulose; all other drugs were dissolved in distilled water. Doses were calculated as the salts, and all injections were made in a volume of $1 \mathrm{ml} / \mathrm{kg}$ body weight. Distilled water was used for all control injections.

The dose of ACPC used in these studies was selected on the basis of earlier studies of ACPC effects in place conditioning and other procedures (Papp and Moryl 1996; Papp et al. 1996). Doses of other drugs were selected on the basis of reports in the literature, and preliminary studies, using two or three doses of each drug, that showed dose-dependent conditioning effects.

\section{Data Analysis}

Data were analyzed using SPSS. An initial within-subjects $t$-test was performed on the data from each of the groups conditioned with the conditioning agent alone (i.e. without ACPC pre-treatment), to confirm a significant effect of conditioning. Then, data from each experiment (except experiment 4 ) were analyzed by analysis of variance, with one within-subjects factor (Pre-post test) and two between-subjects factors, Reward type (experiment 2, six drugs; experiment 3, three drugs; experiment 5, five natural rewards; experiment 6 , two drugs) and Group (four groups in experiments 2, 5 and 6 ; three groups in experiment 3 ). Data from experiment 4 were analyzed similarly, but with a single betweengroups factor, Group. Significant effects were explored using the Student-Newman-Keuls (SNK) test.

\section{RESULTS}

\section{Experiment 1: Effects of ACPC Alone}

As previously reported (Papp et al. 1996). ACPC did not support place conditioning. Table 1 (rows 1 and 2) shows the time spent in the compartment associated with ACPC administration, before and after conditioning in either the white or the black compartment. The time spent in the compartment associated with ACPC did not change significantly in either case $(t(9)=1.15$, 0.22 , respectively; NS). Similarly, ACPC failed to alter preference for either the white or the black side when administered prior to confinement in both compartments (Table 1, rows 3 and $4: t(7)=1.21,1.44$, respectively, NS). ACPC also failed to alter preference for either the white or the black side when administered immediately before the post-conditioning test (Table 1 , rows 5 and 6 : $t(9)=0.79,0.34$, respectively, NS).

\section{Experiment 2: Effects of ACPC on Drug-induced Conditioned Place Preference}

Drug-induced place preference effects are summarized in Figure 1. Control animals conditioned with vehicle showed no changes in preference as a result of conditioning. Animals conditioned with drugs retained their preference for the black compartment: however, significant shifts toward the drug-associated (white) side were observed with all six drugs (nicotine: $\mathrm{t}=2.35, p<$ .05 ; all other drugs, $p<.01$ ). In every case, the druginduced shift in preference was attenuated or abolished by ACPC administered during acquisition of the conditioned response. The effects of ACPC administered during expression of the conditioned response were somewhat variable: ACPC appeared to block the effects of

Table 1. Lack of Effect of ACPC Alone in Place Conditioning Procedures ${ }^{1}$

\begin{tabular}{|c|c|c|c|c|}
\hline & \multicolumn{2}{|c|}{ Veh (1 ml/kg) } & \multicolumn{2}{|c|}{ АСРC (200 mg/kg) } \\
\hline & Pre & Post & Pre & Post \\
\hline Black (A) & $405( \pm 33)$ & $399( \pm 20)$ & $409( \pm 40)$ & $400( \pm 30)$ \\
\hline White (A) & $63( \pm 9)$ & $51( \pm 9)$ & $78( \pm 12)$ & $95( \pm 12)$ \\
\hline Black (B) & $340( \pm 29)$ & $336( \pm 27)$ & $399( \pm 28)$ & $345( \pm 25)$ \\
\hline White (B) & $105( \pm 16)$ & $116( \pm 18)$ & $98( \pm 16)$ & $123( \pm 13)$ \\
\hline Black (E) & $410( \pm 32)$ & $396( \pm 20)$ & $402( \pm 40)$ & $419( \pm 31)$ \\
\hline White (E) & $100( \pm 26)$ & $118( \pm 21)$ & $102( \pm 20)$ & $108( \pm 19)$ \\
\hline
\end{tabular}

${ }^{1}$ Effects of ACPC alone, in four separate experiments. Values are means ( \pm SEM) of time spent in the black and/or white compartments in a postconditioning test. A: vehicle or ACPC administered prior to place conditioning trials in either the black or the white compartment; B: vehicle or ACPC administered prior to confinement in both the black and white compartments: the two sets of $B$ values (black and white) are from a single test in the same group of animals. E: vehicle or ACPC administered prior to the post-conditioning test: the two sets of $\mathrm{E}$ values (black and white) are from a single test in the same group of animals. 

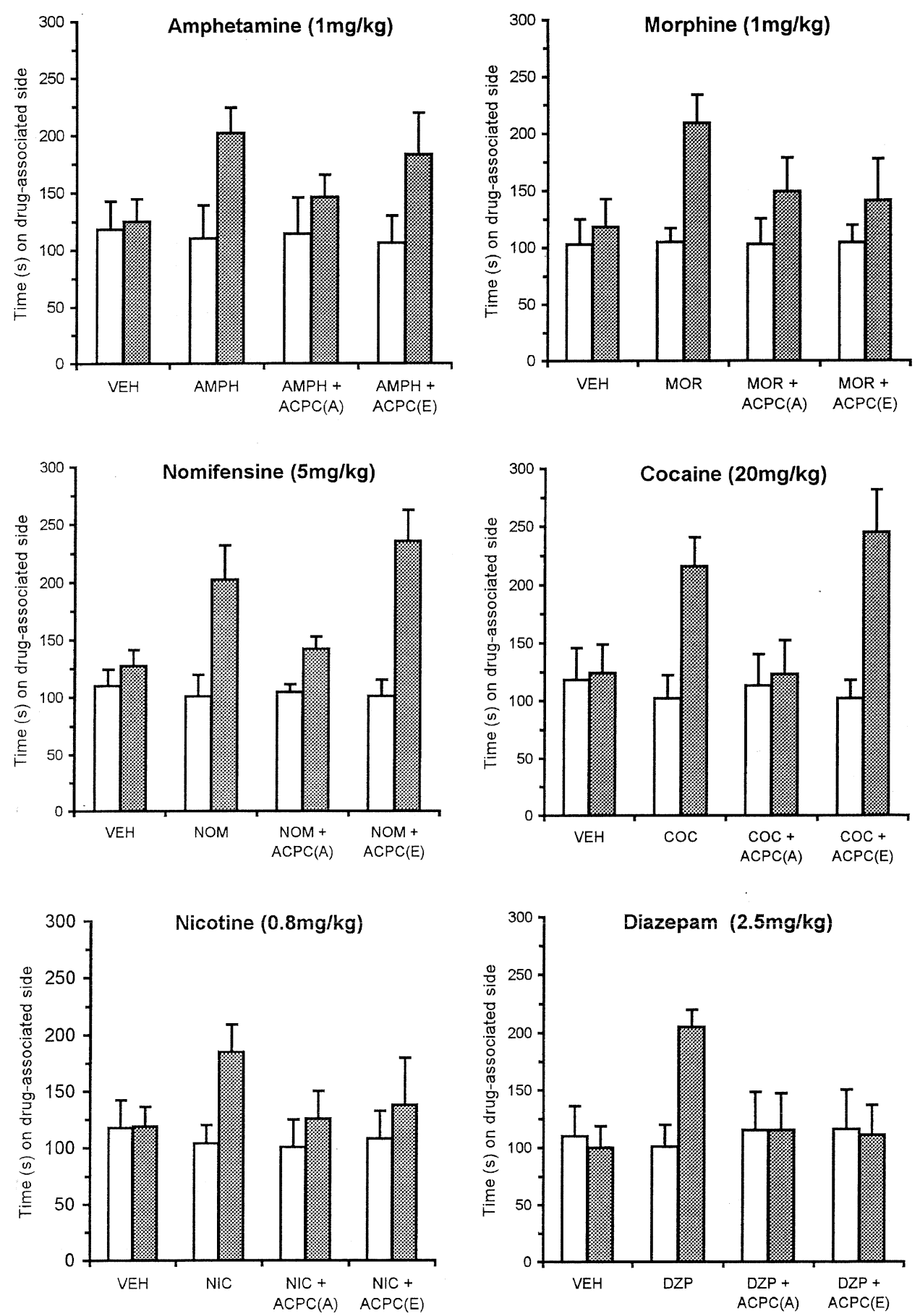

Figure 1. Drug-induced place preference conditioning: effects of ACPC. Values are mean (+SEM) time spent on the drug-associated (white) compartment before (open bars) and after (filled bars) conditioning. In each panel, the first pair of bars shows the data of animals receiving vehicle in the both compartments, and the second pair of bars shows the data of animals receiving vehicle in the black compartment and the conditioning drug in the white compartment. The third and fourth pairs of bars show the data of animals that, in addition to the conditioning drug, also received ACPC, either during acquisition trials (A) or during expression of the conditioned preference in the post-conditioning test $(\mathrm{E}) . \mathrm{n}=8-10$ per group. For further details, see text.

diazepam, morphine and nicotine, but not of amphetamine, cocaine or nomifensine.

Analysis of variance showed a significant Group X Test interaction $\left(\mathrm{F}_{3,211}=16.0, p<.001\right)$, confirming that the extent of conditioning varied between the different experimental groups. However, the main effect of Drug, and all interactions involving this factor were non-significant, including the Group X Test X Drug interaction 

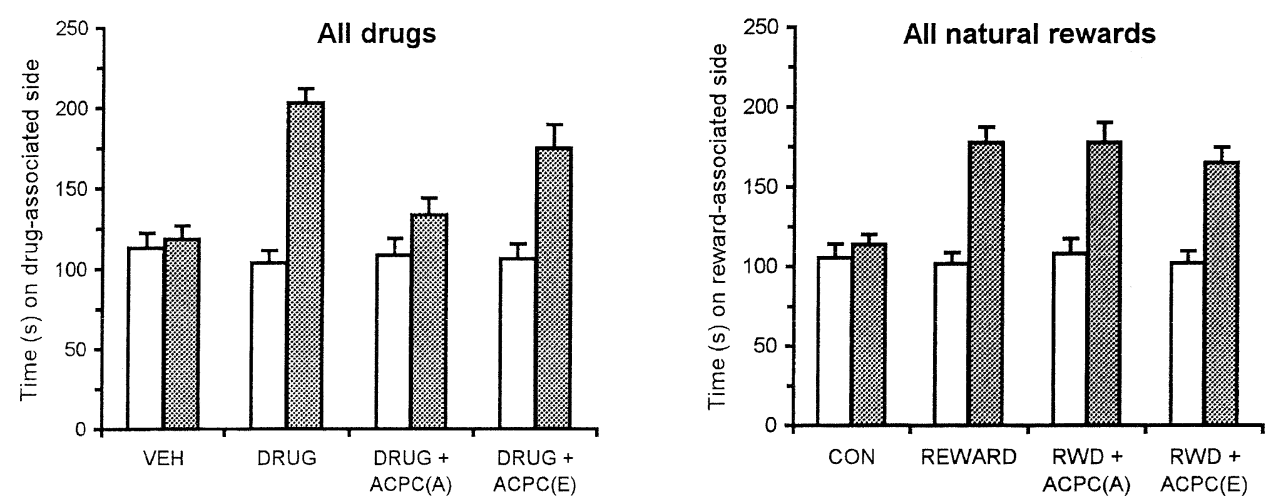

Figure 2. Effects of ACPC on place preference conditioning induced by drugs (left panel) and non-drug natural rewards (right panel). The left panel shows data averaged across all six of the conditioning drugs shown individually in Figure 1; the right panel shows data averaged across all five of the conditions shown individually in Figure 3.

$\left(F_{15,211}=1.3\right)$. This means that between-group differences in conditioning effects did not vary significantly between drugs. The results collapsed across drugs are shown in Figure 2 (left panel). The SNK test confirmed that the groups administered ACPC in acquisition did not differ from vehicle controls in their post-conditioning scores, but both of these groups were significantly lower than the drug-alone groups: i.e., ACPC in acquisition completely blocked drug-induced place conditioning.

The groups administered ACPC during expression of the conditioned response had significantly higher scores than the controls and the groups receiving ACPC in acquisition, and did not differ significantly from the drug-alone groups. This means that ACPC had no overall effect on place conditioning when administered during expression of the conditioned response. However, this conclusion appears to misrepresent the variability of outcome in the groups administered ACPC before expression of the conditioned response (Figure 1). As variability of the response to a single treatment could be concealed in the overall ANOVA by the homogeneity of response to the other three treatments, a further analysis was conducted that was confined to the groups administered ACPC before the post-test. This analysis revealed a significant Test $X$ Drug interaction $\left(\mathrm{F}_{5,45}=4.3, p<.005\right)$. Subsequent $t$-tests on the individual drugs confirmed that significant conditioning effects were present in the groups administered amphetamine $(p<.05)$, cocaine $(p<$ $.002)$ or nomifensine $(p<.001)$, but not in the groups administered morphine, diazepam or nicotine $(p>.2, \mathrm{NS})$, indicating that ACPC attenuated the expression of place conditioning induced by the latter drugs..

\section{Experiment 3: Effects of ACPC on Reward-induced Conditioned Place Preference}

The results of place conditioning with non-drug natural rewards are summarized in Figure 3. Control animals showed no shift in preference as a result of nonrewarded exposure to the apparatus. However, while not abolishing preference for the black compartment, in all five experiments, natural rewards induced a shift in preference toward the reward-associated (white) side (social interaction: $\mathrm{t}=2.31, p<.05$; all other rewards, $p<.01)$. In contrast to the effects on drug-induced place conditioning (Figures 1 and 2), ACPC was without effect, whether administered either during acquisition or during expression of the conditioned response.

ANOVA confirmed a significant Group X Test interaction $\left(\mathrm{F}_{3,192}=11.3, p<.001\right)$, and also confirmed that the Group X Test X Reward interaction was nonsignificant $\left(F_{12,192}=1.0\right)$, indicating that the effect of ACPC on conditioning did not differ as a function of reward type. (Other effects involving the factor Reward were significant, reflecting the greater conditioning in the 22-h food-deprived groups relative to the groups conditioned with the other rewards.) The results collapsed across reward types are shown in Figure 2 (right panel). The SNK test confirmed that post-conditioning scores were significantly greater than control in the three rewarded groups, which did not differ significantly from one another as a function of ACPC treatment.

ACPC had no significant effect on food or sucrose intakes on conditioning trials (Table 2).

\section{Experiment 4: Effect of Chronic ACPC on Drug- induced Conditioned Place Preference}

Drug-induced place preference effects following chronic ACPC treatment are summarized in Figure 4. In vehicle-pretreated animals, morphine, cocaine and diazepam all induced a shift of preference toward the conditioned side (all $p<.01$ ). The effects of chronic ACPC pre-treatment were essentially the same as those observed following acute ACPC treatment during acquisition of the conditioned response (Figure 1). 

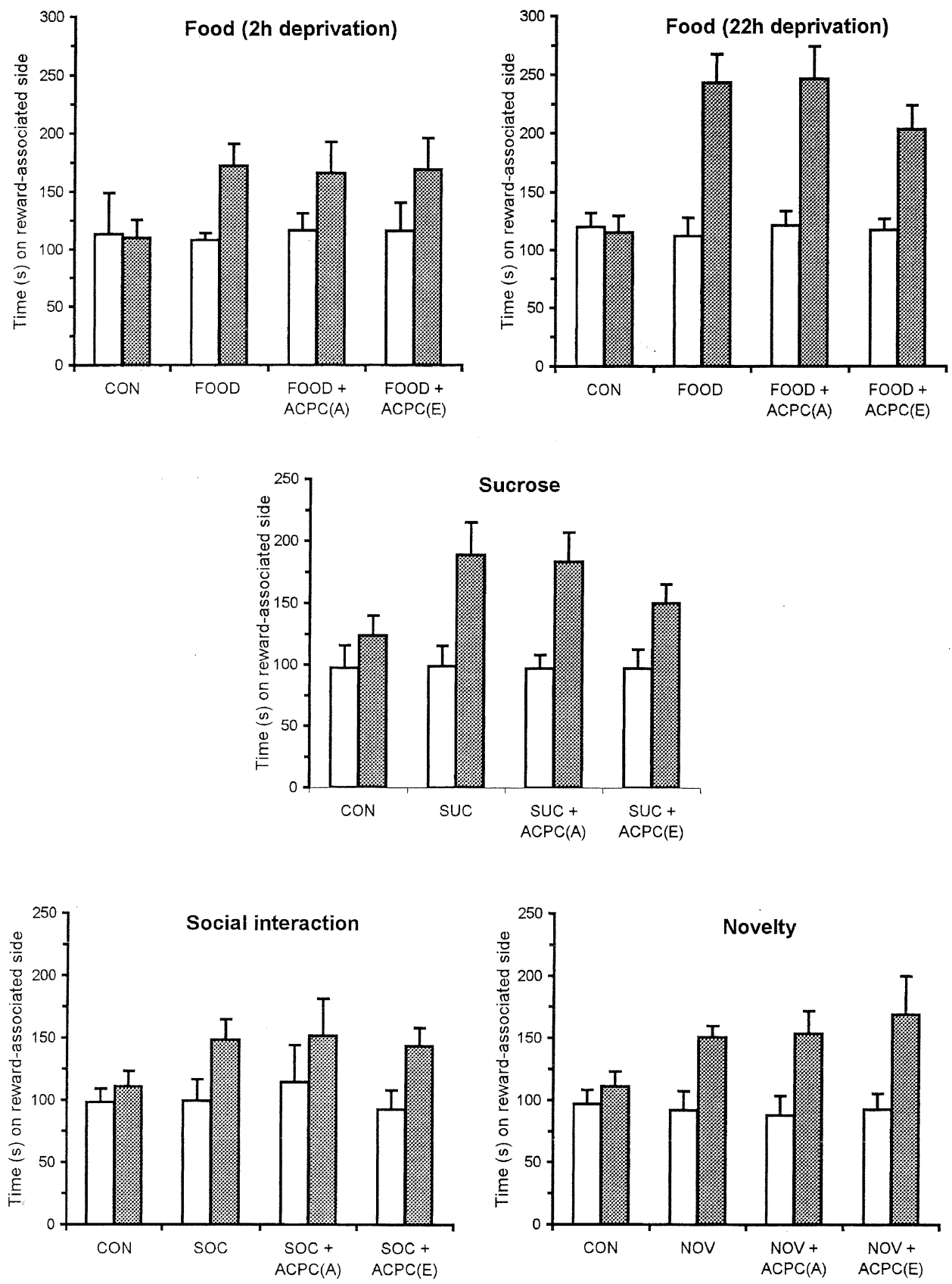

Figure 3. Non-drug reward-induced place preference conditioning: effects of ACPC. Details are as in Figure 1, except that natural rewards were used rather than drug rewards: see text. $n=9-10$ per group.

Analysis of variance confirmed a significant Group X Test interaction $\left(\mathrm{F}_{2,90}=19.1, p<.001\right)$, but the Group $\mathrm{X}$ Test $X$ Drug interaction was non-significant, as were all other effects involving the factor Drug. Place conditioning was completely blocked in the groups pretreated with ACPC (Figure 4); the SNK test confirmed that, following conditioning, the drug-conditioned groups spent more time on the drug-associated side than either the ACPC-treated groups or the vehicle controls, which did not differ significantly from one another.

\section{Experiment 5: Control for State Dependence}

As in earlier experiments, both morphine and cocaine induced a shift of preference toward the conditioned side $(p<.001)$. These effects were attenuated (morphine) or abolished (cocaine) by ACPC, administered during both the acquisition and the expression phases of conditioning (Figure 5). The magnitude of these effects was comparable to those observed when ACPC was administered in acquisition only (Figure 1). 
Table 2. Food/sucrose Intake on Conditioning Days ${ }^{1}$

\begin{tabular}{|c|c|c|c|c|c|c|}
\hline & \multicolumn{2}{|c|}{ Food intake ( $2 \mathrm{~h}$ dep.) } & \multicolumn{2}{|c|}{ Food intake (22 h dep) } & \multicolumn{2}{|c|}{ Sucrose intake } \\
\hline & VEH & ACPC & VEH & ACPC & VEH & ACPC \\
\hline & $\mathrm{n}=\mathbf{2 0}$ & $\mathrm{n}=\mathbf{1 0}$ & $\mathbf{n}=\mathbf{2 0}$ & $\mathrm{n}=\mathbf{1 0}$ & $n=19$ & $n=10$ \\
\hline Day 1 & $1.9(0.2)$ & $1.8(0.5)$ & $13.2(0.7)$ & $12.6(0.7)$ & $8.2(1.1)$ & $9.7(1.8)$ \\
\hline Day 2 & $1.2(0.2)$ & $1.9(0.4)$ & $13.9(0.8)$ & $12.3(0.5)$ & $12.3(1.3)$ & $14.0(1.8)$ \\
\hline Day 3 & $2.8(0.3)$ & $2.7(0.4)$ & $16.6(0.9)$ & $14.8(0.5)$ & $15.7(1.3)$ & $12.4(2.1)$ \\
\hline Day 4 & $2.4(0.2)$ & $3.8(0.4)$ & $16.0(0.6)$ & $15.7(0.7)$ & $17.1(1.3)$ & $16.3(1.6)$ \\
\hline
\end{tabular}

${ }^{1}$ Values are means (SEM). Control values are the mean of the groups administered vehicle during acquisition and ACPC during expression of the conditioned response; ACPC values are the mean of the group administered ACPC during acquisition.

Analysis of variance confirmed a significant Group $\mathrm{X}$ Test interaction $\left(\mathrm{F}_{4,42}=12.9, p<.001\right)$. The SNK test confirmed that, following conditioning, the drug-conditioned groups (groups 2 and 4) spent more time on the drug-associated side than either the ACPC-treated groups (groups 3 and 5) or the vehicle controls (group 1), which did not differ significantly from one another.

\section{Experiment 6: Effects of ACPC on Drug-induced Conditioned Place Aversion}

Figure 6 shows the conditioned place aversion data. As in the place preference conditioning experiments, control animals showed no shift in preference as a result of non-reinforced exposure to the apparatus. However, both naloxone $(\mathrm{t}=4.41, p<.01)$ and picrotoxin $(\mathrm{t}=$ $2.63, p<.05)$ significantly decreased time spent on the drug-associated side in the post-test. In contrast to the effects on drug-induced place preference conditioning (Figures 1 and 2), ACPC, administered either during acquisition or during expression of the conditioned aversive response, was without effect.

ANOVA confirmed a significant Group $X$ Test interaction $\left(\mathrm{F}_{3,71}=14.4, p<.001\right)$. In this case, the Group $\mathrm{X}$ Test $X$ Drug interaction was also significant $\left(\mathrm{F}_{3,71}=4.7\right.$, $p<.01)$, reflecting the fact that conditioning effects were substantially greater with naloxone than with picrotoxin. However, the SNK test confirmed that all of the drug-treated groups differed significantly at posttest from vehicle controls, but not from one another: i.e., conditioning was not significantly affected by ACPC treatment during either acquisition or expression of the conditioned response.

\section{DISCUSSION}

\section{Analysis of Behavioral Processes Mediating the Effect of ACPC on the Acquisition of Place Conditioning}

ACPC blocked the acquisition of place preferences conditioned using drug rewards, but had no effect on place preferences conditioned using natural rewards or on drug-conditioned place aversions. Before drawing the obvious inference, that ACPC selectively blocks the rewarding effects of drugs of abuse, we first consider some alternative explanations of these data.

First, NMDA antagonists are known to induce state dependency: that is, effects learned while under the influence of the drug are only expressed while in the same drug state (Jackson et al. 1992). State dependency can occur, under some conditions, in place conditioning experiments (Laviola and Adriani 1998; Olmstead and Franklin 1997). However, the effects of ACPC on morphine or cocaine CPP were almost identical whether ACPC was administered only during acquisition of the conditioned response (Figure 1), or during both acquisition and expression (Figure 5). Therefore, state dependency can be excluded as an explanation of these data.

Second, we used a biased place conditioning procedure, in which preferences were conditioned toward the initially non-preferred compartment and aversions were conditioned toward the initially-preferred compartment. This means that both conditioning procedures involve an increase in time spent in the non-preferred compartment, which equates to an equalization of the time spent in the two compartments. This could occur as a result of a loss of visual discrimination ability: if the animals were unable to distinguish the two compartments, then they would divide their time equally between the two compartments, and this would be scored as an increase in preference or a decrease in aversion. It is known that NMDA antagonism can impair attention to exteroceptive stimuli (Dai and Carey 1994). There is no direct evidence that NMDA antagonists impair visual discrimination, though this could in principle be a component of their psychotomimetic effects. More important, any effect of this kind would be expressed equally in all behavioral procedures. A decreased ability to discriminate between the two compartments of the place conditioning apparatus could not differentially impair drug-induced place preference conditioning while sparing place aversion conditioning and conditioning to natural rewards. Therefore, this ac- 

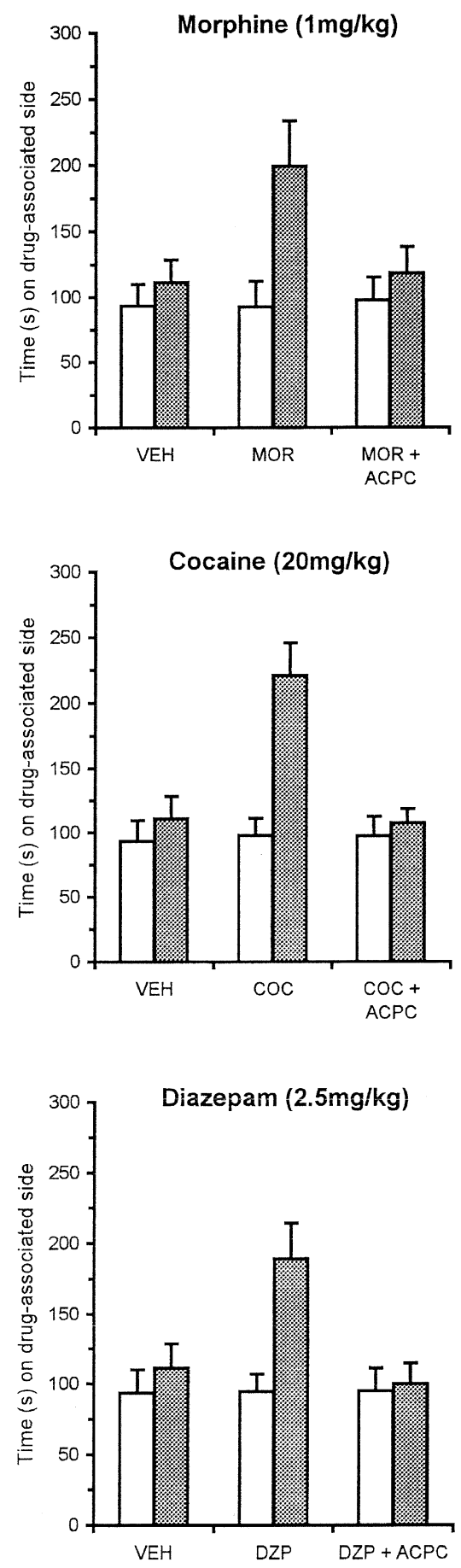

Figure 4. Drug induced place preference conditioning: effects of chronic ACPC pretreatment. In each panel, the first pair of bars shows the data of animals receiving vehicle in both compartments, the second pair of bars shows the data of animals receiving vehicle in the black compartment and the conditioning drug in the white compartment, and the third pair of bars shows the effect of the conditioning procedure in animals chronically pre-treated with ACPC. $\mathrm{n}=$ 9-12 per group. Other details are as in Figure 1.

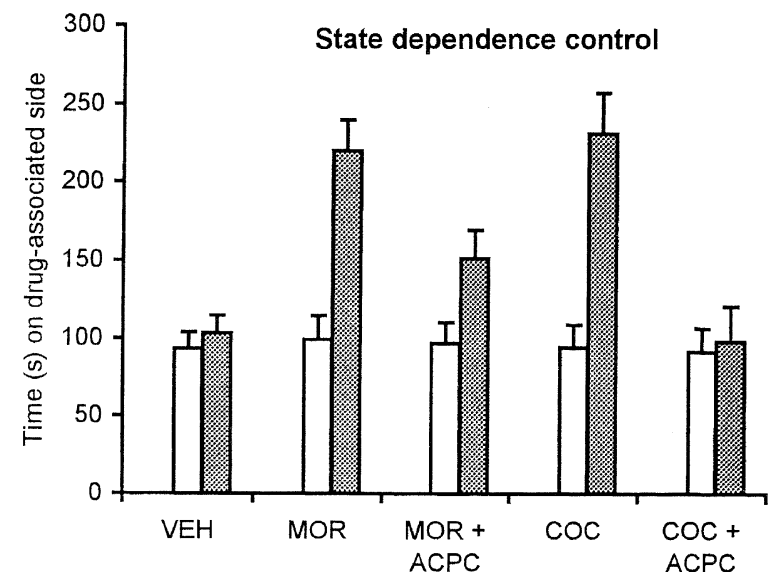

Figure 5. Drug-induced place preference conditioning: control for state dependence. The first pair of bars shows the data of animals receiving vehicle in both compartments; all other data are from animals receiving vehicle in the black compartment and the conditioning drug (morphine or cocaine) in the white compartment. Groups 3 and 5 were pretreated with ACPC on both conditioning trials and the post-conditioning test. $\mathrm{n}=9-10$ per group. Other details are as in Figure 1.

count can be excluded as an explanation of the selective impairment of drug-conditioned preferences by ACPC.

Third, a shift of preference toward the initially nonpreferred compartment could also occur through anxiolytic action, resulting in more rapid habituation to the aversive properties of that environment. This provides another non-associative account of apparent place conditioning in the biased apparatus (Bozarth 1987; Tzschentke 1998). However, there are a number of reasons why the effects of ACPC cannot be explained by a blockade of drug-induced anxiolysis (i.e. an anxiogenic effect of ACPC): (1) while anxiolysis is a plausible hypothesis to explain the conditioning properties of some of the agents used (e.g. diazepam or morphine), it is not a plausible hypothesis to explain the effects of amphetamine or cocaine, which are anxiogenic (Pellow et al. 1985); (2) drug-induced CPP has been demonstrated in the same apparatus as used in the present study when the conditioning drugs were administered in the initially preferred compartment (Papp et al. 1996); (3) if conditioning in this apparatus was based on an anxiolytic effect that is blocked by ACPC, then this effect of ACPC would apply equally to the effects of natural rewards. However ACPC was without effect on place conditioning with natural rewards; (4) at the dose used in the present study, ACPC was without effect in the place conditioning procedure, but at higher doses, ACPC is itself anxiolytic (Anthony and Nevins 1993; Faiman et al. 1994; Trullas et al. 1991).

Fourth, an increase in locomotor activity could also lead to an equalization of time spent in the two com- 

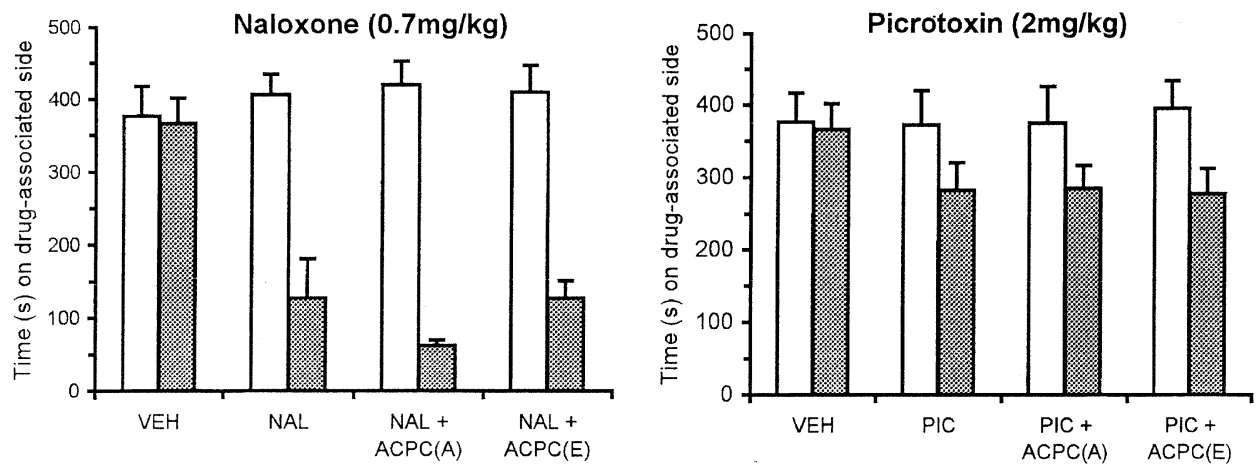

Figure 6. Drug-induced place aversion conditioning. In the drug-conditioned groups, animals received vehicle in the white compartment and naloxone or picrotoxin in the black compartment. Otherwise, all details are as in Figure $1 . \mathrm{n}=9-10$ per group.

partments of a biased conditioning apparatus (Bozarth 1987); therefore, the blockade of CPP by ACPC could arise if ACPC blocked drug-induced locomotor stimulation, with a consequent decrease in conditioned locomotor activity in the post-conditioning test. In fact, ACPC had no effect on amphetamine-induced locomotion in one study (Wesolowska et al. 2000), and increased amphetamine-induced locomotion in another (Przegalinski et al. 1999). Thus, the hypothesis that ACPC blocked place conditioning by blocking druginduced locomotion is untenable, at least in the case of amphetamine.

Finally, a selective blockade of drug-induced preferences, without effect on conditioning using natural rewards, could arise if ACPC blocked the discriminative stimulus effects of the conditioning drugs: it is plausible that a stimulus that is not perceived might be less effective as a reinforcer. However, ACPC has been shown not to alter the discriminative stimulus properties of amphetamine or cocaine (Filip et al. 2000), so this hypothesis also can be excluded, at least in the case of amphetamine and cocaine.

We conclude, from this analysis of alternative explanations, that the most tenable account of the present data is that ACPC selectively blocks drug-induced CPP by selectively blocking either the rewarding properties of the conditioning drugs, or their ability to enter into conditioned associations. We now turn to the mechanisms that might mediate this effect.

\section{Mechanisms of ACPC Effects on the Acquisition of Drug-conditioned Place Preferences}

ACPC is a relatively selective partial agonist at the strychnine-insensitive glycine site on the NMDA receptor complex (Marvizon et al. 1989), and like other glycine receptor partial agonists, acts as functional NMDA antagonist (Carter 1992). Earlier studies have demon- strated that, like ACPC, both uncompetitive (dizocilpine, memantine) and competitive (CGP 37,849) NMDA receptor antagonists block the acquisition of place preferences conditioned with cocaine (Cervo and Samanin 1995; Kotlinska and Biala 2000), amphetamine (Tzschentke and Schmidt 1997) and morphine (Tzschentke and Schmidt 1995; Kim et al. 1996; Popik et al. 1998). However, both classes of directly-acting NMDA antagonist support CPP in their own right (Tzschentke and Schmidt 1995; Papp et al. 1996). By contrast, the glycine site antagonists kynurenic acid and L-701,324 share with ACPC the property of blocking the acquisition of cocaine- and morphine-induced place preference, but not themselves supporting place conditioning (Bespalov et al. 1994; Kotlinska and Biala 1999, 2000). This suggests that blockade of the acquisition of cocaine and morphine CPP, without intrinsic activity in this procedure, may be a general property of compounds that act as functional NMDA antagonists via the strychnine-insensitive glycine receptor. The present data suggest that this property may generalize to the effects of other drugs of abuse, since ACPC blocked the acquisition of place conditioning to all six of the drugs investigated in the present study. To the best of our knowledge, the present study is the first to investigate NMDA receptor involvement in the acquisition of place preferences conditioned to drugs other than cocaine, amphetamine and morphine.

The rewarding properties of drugs of abuse are thought to derive primarily from the enhancement of dopaminergic (DA) activity within the nucleus accumbens. In relation to the drugs used in the present study, the psychostimulants amphetamine, cocaine, and nomifensine are uptake inhibitors, while morphine and nicotine increase the firing rate of meso-accumbens DA neurons by actions within the ventral tegmental area (Di Chiara 1995, 1999). Non-specific DA receptor antagonists such as haloperidol, or more D1-receptor- 
specific antagonists such as SCH-23390 or 31966, block the acquisition of place preferences conditioned using psychostimulants, morphine or nicotine (Acquas et al. 1989; Di Chiara et al. 1991). The basis for the rewarding properties of diazepam, which decreases DA release within the nucleus accumbens (Di Chiara et al. 1991) remains obscure, but, like other drugs of abuse, diazepam-conditioned place preferences are also blocked by haloperidol or SCH-23390 (Spyraki and Fibiger 1988; Di Chiara et al. 1991), as well as the AMPA/kainate antagonist GKY-52466 (Gray et al. 1999). Haloperidol also blocked the acquisition of place preferences conditioned to competitive or uncompetitive NMDA antagonists (Papp and Moryl 1994b).

Intracranial mapping studies have identified the shell region of the nucleus accumbens as a major (though non-exclusive) site supporting drug-induced place preference conditioning (McBride et al. 1999). Within this region, there are extensive bi-directional interactions between DA inputs from the ventral tegmental area and glutamatergic inputs from forebrain sites, such as hippocampus and amygdala, that are known to be involved in place conditioning (Everitt et al. 1991; Tzschentke 1998). These DA-NMDA receptor interactions within the accumbens shell are a likely candidate for a site at which both DA and NMDA receptor antagonists block the acquisition of drug-conditioned place preferences (Tzschentke and Schmidt 1995, 1997; Popik and Kolasiewicz 1999). However, in addition to direct DA-NMDA interactions, DA and glutamate synapses are co-localized on the dendritic spines of medium spiny neurons in the nucleus accumbens (Gerfen 2000; Onn et al. 2000). A substantial literature suggests that the role of DA in incentive learning, as typified by place preference conditioning, is mediated by actions at the D1 receptor subtype (Di Chiara et al. 1991; Beninger and Miller 1998). As DA has some excitatory actions at D1 receptors (Gerfen et al. 1990; Gerfen 2000), D1 antagonists would tend to decrease the activity of target neurons in the nucleus accumbens, and as NMDA receptors are also excitatory, they would share this property with NMDA receptor antagonists. The psychotomimetic and psychostimulant actions of DA agonists, however, are known to be mediated through the D2 receptor subtype (Creese et al. 1976; Ralph et al. 1999; Caine et al. 2000). As DA is inhibitory at D2 receptors (Gerfen et al. 1990; Gerfen 2000), in this case it is D2 agonists that would share with NMDA antagonists the tendency to decrease activity in cells where D2 receptors and NMDA receptors are co-localized.

D1 and D2 receptors are largely segregated in different populations of medium spiny cells, throughout the striatum (Le Moine and Bloch 1995; Smith and Kieval 2000; Gerfen 2000), and associated with different output pathways (Alexander and Crutcher 1990; Gerfen et al. 1990). It follows that the blockade of place conditioning by NMDA antagonists may involve NMDA receptors located on D1-receptor containing accumbens cells, while the psychotomimetic and psychostimulant effects of NMDA antagonists may involve NMDA receptors located on, or interacting functionally with, D2-receptor containing cells. This in turn suggests that glycine receptor antagonists may act to block the acquisition of drug-conditioned place preferences by functional antagonism of NMDA receptors on cells where D1 receptors are co-localized. The mechanisms involved in this putative effect are discussed further below.

\section{Differential Effects of ACPC on Place Conditioning with Drug and Natural Rewards}

In contrast to the wealth of evidence concerning druginduced place conditioning, surprisingly little information is available concerning the involvement of DA and glutamate systems in place conditioning using nondrug natural rewards. However, the evidence, such as it is, suggests that, like drug conditioning, the acquisition of place preferences conditioned using natural rewards, such as food, sucrose, or novelty, requires intact DA transmission, probably at D1 receptors (Spyraki et al. 1982; Agmo et al. 1995; Pierce et al. 1990; Beninger and Miller 1998). We are aware of only a single study of the involvement of glutamate receptors in place conditioning with natural reward: in this study, the acquisition of a novel-object-induced place preference was blocked by the NMDA antagonist dizocilpine (Bevins and Bardo 1999). Thus, the available evidence, though weak, would not immediately support a distinction between drug rewards and natural rewards in terms of the involvement of D1 and NMDA receptors in place preference conditioning.

However, in order for glycine receptor antagonists to have differential effects on place conditioning according to whether the procedure is carried out using drug or natural rewards, either different information must be coded in these two procedures, or if similar information is coded, it must be processed differently. Indeed, there is evidence that in animals self-administering either cocaine or a natural reinforcer (food or water), the two reward types activate different populations of cells in the nucleus accumbens, with fewer than $10 \%$ of phasicallyactive cells responding to both cocaine and natural rewards (Carelli et al. 2000).

A key difference may lie in the degree to which DA synapses in the nucleus accumbens shell are phasically activated by drug and natural rewards. As noted above, a common feature of drugs of abuse, with the exception of diazepam, is that they increase extracellular levels of DA in the nucleus accumbens shell, either by activating DA cell firing or by blocking reuptake of released DA. Recent brain microdialysis studies have confirmed that 
this effect does not undergo tolerance with repeated exposure (Di Chiara 1999). DA release in the accumbens shell is also phasically activated by the presentation of novel natural rewards, but this effect rapidly undergoes habituation, and is absent on second and subsequent presentations (Di Chiara 1999; Schultz 1997; Suri and Schultz 1999). Signals predictive of the later presentation of natural rewards maintain their ability to elicit phasic release of DA in the accumbens shell (Phillips et al. 1989; Schultz 1997; Suri and Schultz 1999); however, this process does not operate during the acquisition of place conditioning, as the reward is present immediately the animal is exposed to the apparatus on conditioning trials. Therefore, drug and natural rewards may differ in that drug rewards are expected to increase extracellular DA levels in the accumbens shell during conditioning trials with the drug, relative to vehicle trials, whereas non-drug natural rewards, being familiar, probably do not increase DA release during conditioning trials with the reward, relative to control trials.

As DA can have excitatory actions at D1 receptors but is inhibitory at D2 receptors (Gerfen 2000), an increase in extracellular DA during drug conditioning would be expected to shift the balance of activity in medium spiny accumbens neurons, in the direction of increased D1-related activity and decreased D2-related activity. Drug rewards, therefore, should lead to an increase in the activity of predominantly D1-bearing cells, at the expense of predominantly D2-bearing cells, during conditioning trials, but natural rewards may not. As the action of glycine receptor antagonists is hypothesized to involve D1-bearing cells (see above), the differential activation of DA synapses by drug rewards, relative to non-drug natural rewards, and the consequent activation of D1-bearing medium spiny neurons, may provide a mechanism to explain the selective action of $\mathrm{ACPC}$ on the acquisition of drug-conditioned place preferences. Activation of D1 receptors, on the cells where D1 and NMDA receptors are co-localized, can amplify the signal arising from stimulation of NMDA receptors (Cepeda et al. 1993; Onn et al. 2000); co-activation of D1 and NMDA receptors leads to the expression of immediate early genes (Konradi et al. 1996; Wang et al. 1994; Gerfen 2000); and prolonged co-activation of D1 and NMDA receptors can lead to longterm potentiation (LTP) of cortico-striatal excitatory transmission (Calabresi et al. 2000). Co-activation of DA and glutamate inputs can also (more commonly) lead to long-term depression (LTD), associated with both D1 and D2 receptor activation and a decrease in AMPAmediated signals (Onn et al. 2000; Calabresi et al. 2000). We hypothesize that glycine receptor antagonists may block drug-induced CPPs by damping down NMDA activity sufficiently to prevent the D1-NMDA receptor synergism necessary for the development of synaptic plasticity in cortico-striatal pathways.
The blockade of place conditioning to natural reinforcers by D1 antagonists (Beninger and Miller 1998) may reflect an additional requirement for a degree of tonic activity at DA synapses (Di Chiara et al. 1991). This may involve stimulation of extrasynaptic D1 receptors (Onn et al. 2000), blockade of which may decrease the signal-to-noise ratio in cortico-striatal pathways (Kiyatkin and Rebec 1996). An additional permissive role of DA in incentive learning has been postulated to explain the fact that D1 antagonists block the acquisition of drug-conditioned place aversions (Di Chiara et al. 1991; Acquas and Di Chiara 1994), which, like preferences conditioned with natural rewards, were unaffected by ACPC in the present study. In this case, the phasic reward signal associated with natural reinforcers (or the aversive signal associated with drugs such as naloxone or pictotoxin), would arise from the activation of other systems, that might well be located outside the nucleus accumbens. It may be significant that, in addition to their rewarding properties, natural reinforcers also have exteroceptive visual, gustatory, and/or olfactory features, which are processed in areas of the brain that may be independent of those involved in druginduced CPPs.

\section{Effects of ACPC on the Expression of Drug- conditioned Place Preferences}

Unlike acquisition, where ACPC blocked place preferences conditioned to all six of the drugs investigated in this study, the effects of ACPC on the expression of place preference conditioning was drug-dependent: ACPC blocked the expression of preferences conditioned to morphine, nicotine and diazepam, but was without effect on the expression of preferences conditioned with cocaine, amphetamine, or nomifensine. These data are largely consistent with those of previous studies, which, however, have been confined to morphine and cocaine. Thus, both the acquisition and the expression of morphine place conditioning was blocked by glycine antagonists (MRZ 2/570 and L-701,324) and by an uncompetitive NMDA antagonist (Popik et al. 1998); in a later study, a competitive NMDA antagonist was shown to block the expression of morphine place preference when administered systemically or directly within the nucleus accumbens or ventral tegmental area (Popik and Kolasiewicz 1999). In contrast, the uncompetitive NMDA antagonist dizocilpine blocked the acquisition but not the expression of cocaine place preference (Cervo and Samanin 1995), and the same results have been reported previously for ACPC (Kotlinska and Biala 2000). The full pattern of effects has been demonstrated with the glycine antagonist L-701,324, which blocked the acquisition of both morphine and cocaine CPP, and blocked the expression of the morphine preference, but had no effect on the expression of the 
cocaine preference (Kotlinska and Biala 1999). However, L-701,324 and another glycine site antagonist did prevent the expression of an amphetamine CPP (Mead and Stephens 1999); it may be significant that, unlike all of the other studies reviewed, this study was conducted in mice rather than rats.

Thus, the present study confirms and extends the earlier data, by demonstrating that the effects reported for cocaine, in rats, are also seen with amphetamine and nomifensine, while the effects reported for morphine are also seen with nicotine and diazepam. Cocaine, amphetamine, and nomifensine are all DA uptake inhibitors, and so may have actions that are relatively localized to physiologically activated DA synapses, while morphine, nicotine and diazepam are not DA uptake inhibitors and may enhance DA transmission in a more indiscriminate manner. Whether this distinction can account for the intriguing pattern of behavioral results remains to be determined.

\section{Implications}

The fact that ACPC blocks the acquisition of CPP to all drugs tested, while a dramatic finding, may be of limited therapeutic relevance. This depends on whether ACPC blocks CPP by preventing drugs from exerting their rewarding effects, or by preventing the formation of conditioned associations between abused drugs and environmental stimuli. In the former case, ACPC could prove a powerful weapon in the therapeutic armamentarium. However, in studies of the effects of glycine antagonists on cocaine self-administration, (+)-HA966 decreased cocaine-maintained responding, but only at high doses which also decreased food-maintained responding (Shoaib et al. 1995), while L-701,324 had no effect (Hyytia et al. 1999). These data suggest that glycine antagonists do not block the rewarding effects of cocaine, and so point to blockade of conditioning as the more likely mechanism for their effects on the acquisition of CPP. In this case, the therapeutic potential of ACPC would be lower, since it is to be expected that conditioned associations between abused drugs and environmental stimuli would be well developed in advance of drug use being identified as problematic. It remains possible, however, that ACPC, or other glycine antagonists, could be used as an adjunct to therapy in counteracting the further development of addiction.

The effects of ACPC on the expression of CPP may be more relevant to therapy, in relation to the prevention of relapse to drug abuse. In this context, the data point to a possible use in the treatment of opiate, cigarette, and benzodiazepine users, but not of psychostimulant users. The following considerations would apply to such use. First, as ACPC does not itself support a CPP, its own abuse potential is probably low. Second, the lack of tolerance to the effects on morphine and diazepam CPP following chronic treatment suggests that chronic treatment regimes could be feasible. Third, the selective effect of ACPC on the expression of drug-conditioned CPP suggests that secondary reinforcers associated with natural non-drug rewards would not be affected. Fourthly, ACPC would not be expected to undermine any conditioning associated with aversive drug effects. Finally, there may be additional benefits deriving from other actions of ACPC. While relapse to substance abuse is driven in part by conditioned responses to environmental stimuli (O'Brien et al. 1998; Tiffany and Carter 1998), two of the major precipitants of relapse are dysphoric moods and the stress associated with interpersonal conflicts (Marlatt and George 1984). The profile of ACPC includes not only the ability to block the secondary reinforcing effects of stimuli associated with drug taking, but also, antidepressant and anxiolytic properties. This cocktail of effects could prove particularly potent as a means of countering relapse to non-psychostimulant drugs.

\section{ACKNOWLEDGMENTS}

The excellent technical assistance of E. Moryl is greatly appreciated. We gratefully acknowledge the helpful comments of Professor D. Stephens on a draft of this manuscript.

\section{REFERENCES}

Acquas EE, Carboni E, Leone P, Di Chiara G (1989): SCH 23390 blocks drug-conditioned place-preference and place aversion: Anhedonia (lack of reward) or apathy (lack of motivation) after dopamine-receptor blockade? Psychopharmacology (Berl) 99:151-155

Acquas EE, Di Chiara G (1994): D1 receptor blockade sterospecifically impairs the acquisition of drug-conditioned place preference and place aversion. Behav Pharmacol 5:555-569

Agmo A, Galvan A, Talamantes B (1995): Reward and reinforcement produced by drinking sucrose: Two processes that may depend on different neurotransmitters. Pharmacol Biochem Behav 52:403-414

Alexander GE, Crutcher MD (1990): Functional architecture of basal ganglia circuits: neural substrates of parallel processing. Trends Neurosci 12:366-375

Anthony EW, Nevins ME (1993): Anxiolytic-like effects of N-methyl-D-aspartate-associated glycine receptor ligands in the rat potentiated startle test. Eur J Pharmacol 250: 317-324

Balster RL (1987): The behavioural pharmacology of phencyclidine. In Meltzer H (ed), Psychopharmacology: The Third Generation of Progress. New York, Raven, pp 1573-1580

Beninger RJ, Miller R (1998): Dopamine D1-like receptors 
and reward-related incentive learning. Neurosci Biobehav Rev 22:335-345

Bespalov A, Dumpis M, Piotrovsky L, Zvartau E (1994): Excitatory amino acid receptor antagonist kynurenic acid attenuates rewarding potential of morphine Eur J Pharmacol 264:233-239

Bevins RA, Bardo MT (1999): Conditioned increase in place preference by access to novel objects: Antagonism by MK-801. Behav Brain Res 99:53-60

Bozarth M (1987): Conditioned place preference: A parametric analysis using systemic heroin injections. In Bozarth M (ed), Methods of Assessing the Reinforcing Properties of Abused Drugs. New York, Springer, pp 241-273

Caine SB, Negus SS, Mello NK, Bergman J (2000): Effects of dopamine D1-like and D2-like agonists in rats trained to discriminate cocaine from saline: influence of experimental history. Exp Clin Psychopharmacol 8:404-414

Calabresi P, Centonze C, Bernardi G (2000): Electrophysiology of dopamine in normal and denervated striatal neurons. Trends Neurosci 23 (Suppl. Basal ganglia, Parkinson's disease and levadopa therapy):S57-63

Carelli RM, Ijames SG, Crumling AJ (2000): Evidence that separate neural circuits in the nucleus accumbens encode cocaine versus "natural" (water and food) reward. J Neurosci 20:4255-4266

Carr GF, Fibiger HC, Phillips AG (1989): Conditioned place preference as a measure of drug reward. In Liebman JM, Cooper SJ (eds), The Neuropharmacological Basis of Reward. Oxford, Clarendon Press, pp 264-319

Carter AJ (1992): Glycine antagonist: Regulation of the NMDA receptor channel complex by the strychnineinsensitive glycine site. Drugs Future 17:595-613

Carter AJ (1995): Antagonists of the NMDA receptor-channel complex and motor coordination. Life Sci 57:917-929

Calcagnetti DJ, Schechter MD (1992): Place conditioning reveals the rewarding aspect of social interaction in juvenile rats. Physiol Behav 51:667-672

Calcagnetti DJ, Schechter MD (1998): Continued trends in the conditioned place preference literature from 1992 to 1996, inclusive, with a cross-indexed bibliography. Neurosci Biobehav Rev 22:827-846

Cepeda C, Buchwald NA, Levine MS (1993): Neuromodulatory actions of dopamine in the neostriatum are dependent upon the excitatory amino acid receptor subtypes activated. Proc Natl Acad Sci USA 90:9576-9580

Cervo L, Samanin R (1995): Effects of dopaminergic and glutamatergic receptors antagonists on the acquisition and expression of cocaine conditioning place preference. Brain Res 673:242-250

Cherkofsky SC (1995): 1-aminocyclopropanecarboxylic acid: mouse to man interspecies pharmacokinetic comparisons and allometric relationships. J Pharm Sci 84:12311235

Creese I, Burt DR, Snyder SH (1976): Dopamine receptor binding predicts clinical and pharmacological potencies of antischizophrenic drugs. Science 192:481-483

Dai H, Carey RJ (1994): The NMDA antagonist MK-801 can impair attention to exteroceptive stimuli. Behav Brain Res 62:149-156
Di Chiara G (1995): The role of dopamine in drug abuse viewed from the perspective of its role in motivation. Drug Alcohol Depend 38:95-137

Di Chiara G (1999): Drug addiction as dopamine-dependent associative learning disorder. Eur J Pharmacol 375:13-30

Di Chiara G, Acquas E, Carboni E (1991) Role of mesolimbic dopamine in the motivational effects of drugs: Brain dialysis and place preference studies. In Willner P, Scheel-Kruger J (eds), The Mesolimbic Dopamine System: From Motivation to Action. Cambridge, Cambridge University Press, pp 367-386

Dunn R, Flanagan D, Martin L, Kerman L, Woods A, Camacho F, Wilmot C, Cornfeldt M, Effland M, Wood P, Carbide R (1992): Stereoselective R-(+) enantiomer of HA966 displays anxiolytic effects in rodents. Eur J Pharmacol 314:207-214

Everitt BJ, Morris KA, O'Brien A, Robbins TW (1991): The basolateral amygdala-ventral striatal system and conditioned place preference: Further evidence of limbic-striatal interactions underlying reward-related processes. Neuroscience 42:1-18

Faiman CP, Viu E, Skolnick P, Trullas R (1994): Different effects of compounds that act at strychnine-insensitive glycine receptors in a punishment procedure. J Pharmacol Exp Ther 270:528-533

Filip M, Papp M, Przegalinski E (2000): Lack of effects of glycineB receptor ligands on the psychostimulant-induced discriminative stimuli in rats. Life Sci 66:737-743

Fossom LH, Von Lubitz DKJE, Lin RCS, Skolnick P (1995): Neuroprotective actions of 1-aminocyclopropanecarboxylic acid (ACPC): A partial agonist at strychnineinsensitive glycine sites. Neurol Res 17:265-270

Gray A, Allison C, Pratt JA (1999): A role for AMPA/kainate receptors in conditioned place preference induced by diazepam in the rat. Neurosci Lett 25:127-130

Gerfen CR (2000): Molecular effects of dopamine on striatalprojection pathways. Trends Neurosci 23 (Suppl. Basal ganglia, Parkinson's disease and levadopa therapy): S64-70

Gerfen CR, Engber TM, Mahan LC, Susel Z, Chase TN, Monsma FJ, Sibley DR (1990): D1 and D2 dopamine receptorregulated gene expression of striatonigral and striatopallidal neurons. Science 250:1429-1432

Grotta J, Clark W, Coull B, Pettigrew LC, Mackay B, Goldstein LB, Meissner I, Murphy D, Laure L (1995): Safety and tolerability of the glutamate antagonist CGS 19755 (selfotel) in patients with acute ischemic stroke. Results of a phase IIa randomized trial. Stroke 26:602-605

Hyytia P, Backstrom P, Liljequist S (1999): Site-specific NMDA receptor antagonists produce differential effects on cocaine self-administration in rats. Eur J Pharmacol 28:9-16

Jackson A, Koek W, Colpaert FC (1992): NMDA antagonists make learning and recall state dependent. Behav Pharmacol 3:415-421

Karcz-Kubicha M, Wedzony K, Zajaczkowski W, Danysz W (1999): NMDA receptor antagonists acting at the glycineB site in rat models for antipsychotic-like activity. J Neural Transm 106:1189-1204

Kim HS, Jang CG, Park WK (1996): Inhibition by MK-801 of morphine-induced conditioned place preference and 
postsynaptic dopamine receptor supersensitivity in mice. Pharmacol Biochem Behav 55:11-17

Kiyatkin EA, Rebec GE (1996): Dopamine modulation of glutatate-induced excitations of neurons in the neotriatum and nucleus accumbens of awake, unrestrained rats. J Neurophysiol 75:142-152

Kleckner NW, Dingledine R (1988): Requirement for glycine in activation of NMDA-receptors expressed in Xenopus oocytes. Science 241:835-837

Koek W, Woods JH, Winger GD (1988): MK-801, a proposed non-competitive antagonist of excitatory amino acid neurotransmission, produces phencyclidine-like behavioral effects in pigeons, rats and rhesus monkeys J Pharmacol Exp Ther 245:969-974

Konradi C, Leveque JC, Hyman SE (1996): Amphetamine and dopamine-induced immediate early gene expression in striatal neurons depends on postsynaptic NMDA receptors and calcium. J Neurosci 16:4231-4239

Kotlinska J, Biala G (1999): Effects of the NMDA/glycine receptor antagonist L-701,324, on morphine- and cocaine-induced place preference. Pol J Pharmacol 51:323-330

Kotlinska J, Biala G (2000): Memantine and ACPC affect conditioned place preference induced by cocaine in rats. Pol J Pharmacol 52:179-185

Laviola G, Adriani W (1998): Evaluation of unconditioned novelty-seeking and d-amphetamine-conditioned motivation in mice. Pharmacol Biochem Behav 59:1011-1020

Le Moine C, Bloch B (1995): D1 and D2 dopamine receptor gene expression in the rat striatum: sensitive cRNA probes demonstrate prominent segregation of D1 and D2 mRNAs in distinct neuronal populations of the dorsal and ventral striatum. J Comp Neurol 355:418-426

Marlatt G, George WH (1984): Relapse prevention: Introduction and overview of the model. Brit J Addic 79: 261-273

Marvizon JC, Lewin AH, Skolnick P (1989): 1-aminocyclopropane carboxylic acid: A potent and selective ligand for the glycine modulatory site of the N-methyl-Daspartate receptor complex. J Neurochem 52:992-994

McBride WJ, Murphy JM, Ikemoto S (1999): Localization of brain reinforcement mechanisms: Intracranial self-administration and intracranial place-conditioning studies. Behav Brain Res 101:129-152

Mead AN, Stephens DN (1999): CNQX but not NBQX prevents expression of amphetamine-induced place preference conditioning: A role for the glycine site of the NMDA receptor, but not AMPA receptors. J Pharmacol Exp Ther 290:9-15

Meldrum B (1985): Possible therapeutic application of antagonists of excitatory amino acud neurotransmitters. Clin Sci 68:113-123

Nahum-Levy R, Fossom LH, Skolnick P, Benveniste M (1999): Putative partial agonist 1-aminocyclopropanecarboxylic acid acts concurrently as a glycine-site agonist and a glutamate-site antagonist at N-methyl-Daspartate receptors. Mol Pharmacol 56:1207-1218

O'Brien CP, Childress AR, Ehrman R, Robbins SJ (1998): Conditioning factors in drug abuse: Can they explain compulsion? J Psychopharmacol 12:15-22

Olmstead MC, Franklin KB (1997): The development of a conditioned place preference to morphine: effects of lesions of various CNS sites. Behav Neurosci 111: 1313-1323

Olney JW, Labruyere J, Price MT (1989): Pathological changes induced in cerebrocortical neurons by phencyclidine and related drugs. Science 244:1360-1362

Onn S-P, West AR, Grace AA (2000): Dopamine-mediated regulation of striatal neuronal and network interactions. Trends Neurosci 23 (Suppl. Basal ganglia, Parkinson's disease and levadopa therapy):S48-56

Papp M, Moryl E (1994a): Antidepressant activity of noncompetitive and competitive NMDA receptor antagonists in a chronic mild stress model of depression. Eur J Pharmacol 263:1-7

Papp M, Moryl E (1994b): Attenuation by haloperidol of the place preference conditioning induced by non-competitive and competitive NMDA antagonists. Behav Pharmacol 5(Suppl 1):108

Papp M, Moryl E (1996): Antidepressant-like effects of 1-aminocyclopronapencarboxylic acid and d-cycloserine in an animal model of depression. Eur J Pharmacol 316:145-152

Papp M, Moryl E, Maccecchini ML (1996): Differential effects of agents acting at various sites of the NMDA receptor complex in a place preference conditioning model. Eur J Pharmacol 317:191-196

Parker LA (1992): Place conditioning in a three- or fourchoice apparatus: Role of stimulus novelty in druginduced place conditioning. Behav Neurosci 106:294306

Paul IA, Nowak G, Layer RT, Popik P, Skolnick P (1994): Adaptation of the N-methyl-D-aspartate receptor complex following chronic antidepressant treatments J Pharmacol Exp Ther 269:95-102

Pellow S, Chopin P, File SE, Briley M (1985): Validation of open:closed arm entries in an elelvated plus-maze as a measure of anxiety in the rat. J Neurosci Meth 14:149167

Phillips AG, Pfauss JD, Blaha CD (1989): Dopamine and motivated behaviour: Insights provided by in vivo analyses. In Willner P, Scheel-Kruger J (eds), The Mesolimbic Dopamine System: From Motivation to Action. Cambridge, Cambridge University Press, pp 199-224

Pierce RC, Crawford CA, Nonneman AJ, Mattingley BA, Bardo MT (1990): Effect of forebrain dopamine depletion on novelty-induced place preference behavior in rats. Pharmacol Biochem Behav 36:321-325

Popik P, Kolasiewicz W (1999): Mesolimbic NMDA receptors are implicated in the expression of conditioned morphine reward. Neunyn-Schmiedebergs Arch Pharmacol 359:288-294

Popik P, Mamczarz J, Fraczek M, Widla M, Hesselink M, Danysz W (1998): Inhibition of reinforcing effects of morphine and naloxone-precipitated opioid withdrawal by novel glycine site and uncompetitive NMDA receptor antagonists. Neuropharmacology 37:1033-1042

Przegalinski E, Siwanowicz J, Chojnacka-Wojcik E (1999): Lack of effect of a glycine(B) receptor partial agonist on amphetamine-induced sensitization in mice. Pol J Pharmacol 51:385-390

Ralph RJ, Varty GB, Kelly MA, Wang YM, Caron MG, 
Rubinstein M, Grandy DK, Low MJ, Geyer MA (1999): The dopamine D2 but not D3 or D4 receptor subtype is essential for the disruption of prepulse inhibition produced by amphetamine in mice. J Neurosci 19:46274633

Rundfeldt C, Wlaz O, Löscher W (1994): Anticonvulsant activity of antagonists and partial agonists for the NMDA receptor-associated glycine site in the kindling model of epilepsy Brain Res 653:125-130

Scatton B (1993): The NMDA receptor complex. Fundament Clin Pharmacol 7:389-400

Schechter DM, Calcagnetti DJ (1993): Trends in place preference conditioning with a cross-indexed bibliography, 1957-1991. Neurosci Biobehav Rev 17:21-41

Schultz W (1997): Dopamine neurons and their role in reward mechanisms. Curr Opin Neurobiol 7:191-197

Shoaib M, Shippenberg TS, Goldberg SR, Schindler CW (1995): Behavioural studies with the glycine partial agonist (+)-HA966 on cocaine-induced locomotor activity and reinforcement. Behav Pharmacol 6:568-576

Smith Y, Kieval JC (2000): Anatomy of the dopamine system in the basal ganglia. Trends Neurosci 23 (Suppl. Basal ganglia, Parkinson's disease and levadopa therapy): S28-33

Spyraki C, Fibiger HC (1988): A role of the mesolimbic dopamine system in the reinforcing properties of diazepam. Psychopharmacology (Berl) 94:133-137

Spyraki C, Fibiger HC, Phillips AG (1982): Attenuation by haloperidol of place preference conditioning using food reinforcement. Psychopharmacology (Berl) 77:379-382

Suri RE, Schultz W (1999): A neural entwork model with dopamine-like reinforcement signal that learns a spatial delayed response task. Neuroscience 91:871-890

Sveinbjornsdottir S, Sander JWAS, Upton D, Thompson PJ, Patsalos PN, Hirt D, Emre M, Lowe D, Duncan JS (1993): The excitatory amino acid antagonist D-CPP-ene (Sdz Eaa-494) in patients with epilepsy. Epilepsy Res 16:165-174
Tiffany ST, Carter BL (1998): Is craving the source of compulsive drug use? J Psychopharmacol 12:23-30

Trullas R, Folio T, Young A, Miller R, Boje K, Skolnick P (1991): 1-aminocyclopropanecarboxylates exhibit antidepressant and anxiolytic actions in animal models. Eur J Pharmacol 203:379-385

Tzschentke T (1998): Measuring reward with the conditioned place preference paradigm: A comprehensive review of drug effects, recent progress and new issues. Prog Neurobiol 56:613-672

Tzschentke TM, Schmidt WJ (1995): N-methyl-D-aspartic acid-receptor antagonists block morphine-induced conditioned place preference in rats. Neurosci Lett 193: $37-40$

Tzschentke TM, Schmidt WJ (1997): Interactions of MK-801 and GYKI 52466 with morphine and amphetamine in palce preference conditioning and behavioural sensitisation. Behav Brain Res 84:99-107

Von Lubitz DKJE, Lin RCS, McKenzie RJ, Devlin TM, McCabe TR, Skolnick P (1992): A novel treatment of global ischaemia with a glycine partial agonist. Eur J Pharmacol 219:153-158

Wang JQ, Daunais JB, McGinty JF (1994): NMDA receptors mediate amphetamine-induced regulation of zif/268 and preprodynorphin mRNA expression in rat striatum. Synapse 18:343-353

Wesolowska A, Borycz J, Chojnacka-Wojcik E, Przegalinski E (2000): Lack of effect of repeated treatment with a glycineB receptor partial agonist on the amphetamineinduced hyperactivity in rats. Pol J Pharmacol 52:203207

Willetts J, Balster RL, Leander JD (1990): The behavioural pharmacology of NMDA receptor antagonists. Trends Pharmacol Sci 11:423-428

Witkin JM (1995): Role of NMDA receptor in behavioural effects of drugs. In Stone TW (ed), CNS Neurotransmitters and Neuromodulators: Glutamate. Boca Raton, FL, CRS Press, pp323-350 